\section{Asian mental health and use of drama therapy for acculturative family distancing in immigrant families}

\section{Bharat R. Sampathi \\ UC Irvine School of Medicine, Irvine, CA, USA}

For centuries, Asian populations have struggled with obtaining and maintaining treatment for psychiatric illnesses when compared to their European counterparts. A large part of this issue stems from cultural values and beliefs regarding mental illness. Firstly, psychotherapy may be seen as a weakness and breech of familial privacy. ${ }^{1}$

Additionally, Asian populations have somaticized psychiatric illnesses, perseverating on physical symptoms rather than a potential emotional source. Eastern populations, on the other hand, have been shown to be much more likely to consult mental health professionals for their emotional concerns. 2,3

It has also been documented that some Asian families believe seeking psychiatric help brings shame to one's family. Rather, they often believe one should be able to exercise individual willpower and avoid negative thoughts. ${ }^{4}$ Concern for stigmatization has also led some Asian families to hide psychiatrically ill family members at home until severe and damaging psychotic events occur. 5

First generation Asian Americans are more accepting of mental illness and are more likely to seek psychiatric help due to increased acculturation to the Western world. ${ }^{6}$ However, the cultural gap between Asian Americans and their immigrant parents continues to exist. Acculturative family distancing (AFD) occurs when an immigrant family attempts to unite distinct cultural worlds. Parents find it hard to create space for new beliefs on mental health, for example, and conflicts consequently arise as families struggle to maintain a collaborative bicultural identity. ${ }^{7}$ A study in 2010 indicated that children in families with greater AFD were associated with a higher risk for clinical depression and depressive symptoms. ${ }^{8}$
Research has shown that drama therapy has been quite effective in helping treat various psychiatric illnesses. To date, there has been minimal documentation on workshops using drama therapy to address AFD in Asian families. The Stanford Communication Health Interactive for Parents and Others (CHIPAO) is a group of Asian American attendings, residents, and students at the Stanford School of Medicine that perform interactive skits designed to address and minimize AFD in Asian American families with immigrant parents. This initiative was built after two separate youth suicide clusters that involved mainly Asian American males in Palo Alto, California from 2009 to 2015.

During each event, members act out scenarios of family conflict (bad grades, drugs, self-harm, sexuality) with a dose of comedy to lighten the mood. A moderator then leads a discussion with the audience to discuss the conflict at hand. Lastly, the team performs an improved rendition of the same skit using solutions from the discussion. Throughout the workshop, we alleviate the stigma surrounding mental health and remain entirely open to the audience, stressing that it is both normal and necessary for parents to talk about anxiety, depression, and more.

It will be interesting to monitor AFD as first-generation children become parents. It is possible that the children of these firstgeneration families, like myself who have lived through these experiences, may be more equipped to address these issues as they grow older. Furthermore, with the rise in globalization both economically and culturally, it is exceedingly possible that future immigrants may be from regions so advanced that cultural disparities across the globe diminish.

\section{References}

1. Lin T, Lin, M. Service delivery issues in Asian North American communities. Am J Psychiatry 1978;135:454-7.

2. Brown TR, Stein KM, Huang K, Harris DE. Mental illness and the role of mental health facilities in Chinatown. In: Sue S, Wagner $N$ (Eds.). Asian Americans: Psychological P1: GDX
Correspondence: Bharat Reddy Sampathi, UC Irvine School of Medicine, 1001 Health Sciences Rd, Irvine, CA 92617, USA.

Tel.: +1.650.823.3426.

E-mail: bsampath@uci.edu

Key words: Asian populations, mental health, immigrant family, therapy.

Conflict of interest: the author declares no potential conflict of interest.

Funding: none.

Received for publication: 2 August 2018. Accepted for publication: 2 August 2018.

This work is licensed under a Creative Commons Attribution-NonCommercial 4.0 International License (CC BY-NC 4.0).

CC Copyright B.R. Sampathi, 2018

Licensee PAGEPress, Italy

Mental Illness 2018; 10:7806

doi:10.4081/mi.2018.7806

Mental Health Services. Palo Alto, CA: Science and Behavior Books: 1983. pp. 212-31.

3. Sue S, Morishima JK. The mental health of Asian Americans. San Francisco: Jossey-Bass; 1982.

4. Root MP. Guidelines for facilitating therapy with Asian American clients. Psychotherapy 1985;22:349-56.

5. Lin TY, Tardiff K, Donetz G, Goretsky W. Ethnicity and patterns of help seeking. Cult Med Psychiatry 1978;2:3-13.

6. Atkinson DR, Gim RH. Asian American cultural identity and attitudes toward mental health services. J Couns Psychol 1989;36:209-12.

7. Birman D, Poff M. Immigration. Intergenerational Differences in Acculturation. 2011. Available from: http://www.child-encyclopedia. com/immigration/a c cordingexperts/intergenerational-differencesacculturation

8. Hwang WC, Wood JJ, Fujimoto K. Acculturative Family Distancing (AFD) and Depression in Chinese American Families. J Consult Clin Psychol 2010;78:655-67. 